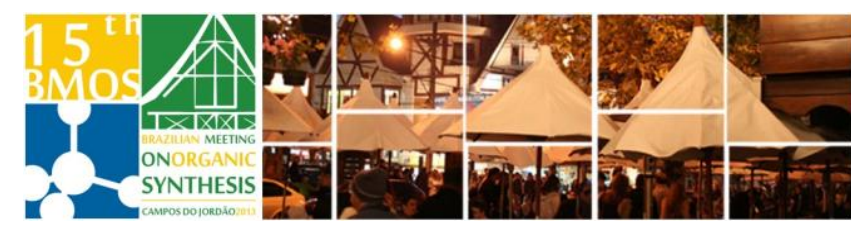

\title{
1,3-Dipolar cycloadditions for the synthesis of low aggregation chlorins: A methodological study
}

\author{
Juliana M. de Souza; ${ }^{a}$ Francisco F. de Assis; ${ }^{a}$ Carla M. B. Carvalho, ${ }^{a}$ José A. S. \\ Cavaleiro, ${ }^{\mathrm{b}}$ Timothy J. Brocksom ${ }^{\mathrm{a}}$ and Kleber T. de Oliveira ${ }^{\mathrm{a} *}$ \\ a Universidade Federal de São Carlos - UFSCar, Departamento de Química,13565-905, São Carlos, SP, \\ Brazil. 'Departamento de Química, Universidade de Aveiro, Portugal. \\ *e-mail: kleber.oliveira@ufscar.br; www.lqbo.ufscar.br
}

Keywords: cycloadditions, synthesis, chlorins

\section{INTRODUCTION}

Porphyrins are a class of heterocyclic compounds with comprehensive applications in technology, catalysis, materials science as well as in medicine. ${ }^{1}$ Chlorin derivatives are natural or synthetic porphyrinoids with one of the pyrrole rings reduced at the $\beta$ position. So far no synthetic approach has proven to be as efficient in producing chlorins as cycloaddition reactions. For example, five member rings formed by the 1,3-dipolar cycloadditions on porphyrins, ${ }^{2}$ are essential to produce compounds with low aggregation in solution, thus providing new molecules for use in photodynamic therapy (PDT) studies. Therefore, this work aims at the synthesis of new chlorin derivatives with low aggregation. Several conditions are being tested in order to provide a comprehensive study on the reactivity of dipoles (azomethine ylide) and dipolarophiles (porphyrins) under mild conditions.

\section{RESULTS AND DISCUSSION}

Initially, we synthesized the amine $\mathbf{4}$ in two wellknown steps (Scheme 1). ${ }^{3}$
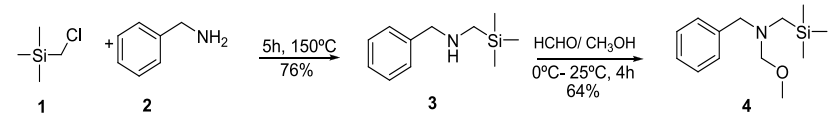

Scheme 1. Synthesis of compound 4.

Synthesis of meso-tetrakis(pentafluorophenyl) porphyrin (TPPF) (5) was performed using pentafluorobenzaldehyde and pyrrole, obtaining TPPF in $8 \%$ yield after laborious purifications. Metallation of 5 with $\mathrm{NiCl}_{2} \cdot 6 \mathrm{H}_{2} \mathrm{O}$ in DMSO furnished 6 in $95 \%$ yield. $^{4}$

After preparation of the metallated porphyrin 6, we studied the 1,3-dipolar reaction with one-pot generated azomethine ylide 7 at room temperature, under several dipole concentrations, obtaining the chlorin $\mathbf{8}$ and the isobacteriochlorin $\mathbf{9}$ in different proportions (Table 1).

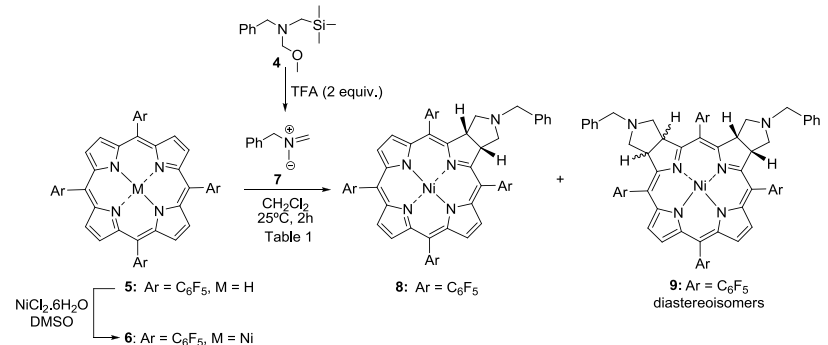

Scheme 2. Products of the cycloaddition of porphyrin 6 .

Table 1. Yields obtained with different amounts of 4.

\begin{tabular}{c|c|c|c}
\hline $\begin{array}{c}\text { Equivalents of } \mathbf{4} \\
\text { (dipole precursor) }\end{array}$ & \multicolumn{3}{|c}{ Product Yields (\%) } \\
\cline { 2 - 4 } & $\mathbf{6}$ & $\mathbf{8}$ & $\mathbf{9}$ \\
\hline 5 & 80.3 & 10 & 0 \\
\hline 10 & 63 & 22.4 & traces \\
\hline 15 & 53 & 36.6 & 5.3 \\
\hline 20 & 46 & 40 & 6.1 \\
\hline 25 & 36.7 & 45.8 & 12.4 \\
\hline 30 & 0 & traces & 65.5 \\
\hline
\end{tabular}

\section{CONCLUSION}

Chlorin 8 and isobacteriochlorin 9 derivatives have been obtained under mild conditions using a 1,3dipolar cycloaddition procedure. Also, compounds 8 and 9 revealed low aggregation in solution due to the "L" shape of these molecules. ${ }^{2 \mathrm{C}}$ Currently, we are finishing up the characterizations, and evaluating the photophysical properties of such products.

\section{ACKNOWLEDGEMENTS}

The authors thank FAPESP (2013/06532-4, 2012/14328-5, 2012/24098-4, 2011/17177-5 and 2011/13993-2), CNPq and CAPES for financial support and fellowships.

\section{REFERENCES}

1 Lindsey, J. S. Accounts of Chemical Research 2010, 43, 300-311.

2 a) Silva, Ana M. G., Tomé, A. C., Neves, M. G. P. M. S., Silva, A. M. S. Cavaleiro, J. A. S. Chem. Commun. 1999, 1767-1768. b) Silva, Ana M. G., Tomé, A. C., Neves, M. G. P. M. S., Silva, A. M. S. Cavaleiro, J. A. S. J. Org Chem 2005, 70, 2303-2314. c) de Assis, F. F.; Souza, J. M.; Assis, B. H. K.; Brocksom, T. J.; de Oliveira, K.T.; Dyes and Pigments 2013, 98, 153-159.

3 Thaqi, A.; Scott, J.L.; Gilbert, J.; Sakoff, J.A.; McCluskey, A. Eur. J. Med. Chem., 2010, 45, 1717-1723.

${ }^{4}$ Kadish, K.M.; Araullo-McAdams, C.; Han, B.C.; Franzen, M.M. J. Am. Chem. Soc. 1990, 112, 8364-8368. 